\title{
5 Research Square

\section{Bioaccumulation of Trace Metals and Genotoxicity Responses in Liza aurata as an Indicator of Industrial Pollution}

Funda Turan ( $\nabla$ funda.turan@iste.edu.tr)

Iskenderun Technical University: Iskenderun Teknik Universitesi https://orcid.org/0000-0002-02576009

\section{Bertan Yilmaz}

Cukurova University: Cukurova Universitesi

M. Lutfi Yola

Hasan Kalyoncu Üniversitesi: Hasan Kalyoncu Universitesi

Aysegul Eregenler

Iskenderun Technical University: Iskenderun Teknik Universitesi

\section{Seda llgaz}

Cukurova University: Cukurova Universitesi

Hale Oksuk

Cukurova University: Cukurova Universitesi

\section{Research Article}

Keywords:

Posted Date: April 5th, 2021

DOl: https://doi.org/10.21203/rs.3.rs-363167/v1

License: (c) (i) This work is licensed under a Creative Commons Attribution 4.0 International License. Read Full License 


\section{Abstract}

Heavy metal contamination in the coastal and marine ecosystems is becoming a progressively serious risk to aquatic organisms and humans. This study reports the genetic damage and the accumulations of trace metals of $L$. aurata as a bioindicator species in the Payas coast of Iskenderun Bay, North-Eastern Mediterranean by COMET Assay. Fish were seasonally collected from a sampling site and a reference site for one year. Physicochemical parameters in water and trace metals in the tissues of fish collected from these sites were determined by electrochemical techniques. The high DNA damage frequency at the $L$. aurata was observed in the Payas coast of Iskenderun bay compared to the reference site because of pollutants that the detected high levels of $\mathrm{Cd}, \mathrm{Pb}, \mathrm{Fe}$ and $\mathrm{Cu}$ accumulation in $\mathrm{L}$. aurata were exceed the maximum levels allowed by the national and international limit values. A significant positive correlation between $\mathrm{Cd}, \mathrm{Pb}, \mathrm{Hg}, \mathrm{Cr}, \mathrm{Fe}, \mathrm{Zn}$ and $\mathrm{Cu}$ accumulations and DNA damage parameters was reported in the present study. Besides, we reported firstly, that it can be used successfully the electrochemical technique in the determination of trace metal concentrations in mullet. Consequently, obtained data indicate that $L$. aurata constitutes a useful tool as a sentinel organism for biomonitoring of the coastal ecosystem.

\section{1.introduction}

Environmental pollution by trace metals is critical worldwide trouble. Toxic heavy metals and nonbiodegradable elements cause detrimental effects to terrestrial and aquatic organisms. Both natural and anthropogenic events generally generate heavy metals that contaminate the aquatic habitats through drainage channels, river inputs and atmospheric depositions. Especially, an extensive degree of unprocessed or inadequately treated wastewaters from intense industrial activities and domestic drainage discharge into rivers, which degrade the water quality and generate significant damaging impacts on marine ecosystem. Human health is threatened by trace metals contamination to toxic levels in different water colons and its living organisms, which lead to ecological damage. Therefore, the toxic pollutants in marine ecosystems with a wide variety of contaminants have become a major concern for the past decade (Anandkumar et al. 2019; Turan et al. 2020a).

The interaction of DNA-damaging agents such as heavy metals with the genetic material of the cell in relation to the consequences on the health of the aquatic organism is among the scope of Genotoxicology. DNA integrity can be damaged owing to environmental toxic substances causing genotoxic disorders, which leads to induction of mutations, chromosomal abnormalities, tumors, and cell death in the aquatic organism (Bogoni et al. 2014). Hence, it is crutial to evaluate the effect of genotoxins and the amount of DNA chain breakage in aquatic ecosystems both as an indicator of genotoxicity and a biomarker in ecological monitoring (Turan et al. 2020b). Comet testing is widely applied to study the genotoxic effects of contaminants on fish by predicting DNA damage to evaluate genetic damage due to xenobiotic exposure, and is a reliable, sensitive, and quick technique used for the detection of DNA strand breakage and alkali-labile regions in cell of organism (Martins and Costa 2017; Turan et al. 2020a). 
Fish are one of the important aquatic organisms widely used as a model for evaluating the health of aquatic ecosystems, considered as a bioindicator of environmental pollution due to their sensitive responses to biochemical and physiological changes in the ecosystem (De Lemos et al. 2007; Cazenave et al. 2009). Determination of aquatic organism reactions to various pollutants, such as heavy metal, can be performed by integrating a range of biomarkers as a significant instrument in the marine ecosystem (Dalzochio et al. 2017). Also, Fish, as a valuable human food, can also provide information on the bioavailability of pollutants, promoting the process of bio-magnification (heavy metals) and threats to human health. Bioassay researches using fish have stated an important correlation with DNA damage in human cells exposed to mutagens (Marcon et al. 2010). The fish species selected for the present study Golden grey mullet, Liza aurata, is generally distributed in the Mediterranean and the Black Sea, as well as along the Atlantic coast from Scotland and the southern coast of Norway and Sweden south towards Morocco (Turan 2016). Together with other members of the Mugilidae family, they inhabit coastal lagoons, marine neritic, marine coastal/supratidal, and estuaries. The feeding behaviour of these fish is generally characterized by regular contact with the sediment. Therefore, they are virtuous candidates as a biomarker for monitoring contamination of water by xenobiotics over a wide range of lipophilicity (Pacheco et al. 2005; D'Costa et al. 2017), and these species are known as bioconcentration of toxic pollutants (Bouzenda et al. 2017).

The Mediterranean is under a great toxicological threat due to its unique hydrographic features and high anthropological activity pressure (Storelli et al. 2011; Ayas et al. 2018). In Payas-Dörtyol coast of Iskenderun Bay is located on the Mediterranean coast of Turkey at which, there are many important international industrial plants (iron-steel plants, cement plants, fertilizer plants, liquefied petroleum gas plants, oil transfer docks, and other industrial plants) (Yılmaz et al. 2010, Duysak 2019). In this region, iron and steel industries hold the most important place among these industries (Yücel and Çam 2021). There have been several studies that report heavy metal accumulation in numerous fish species and seawater, sediment and sestons in the Iskenderun Bay, the North-Eastern Mediterranean (Türkmen et al. 2005; Turan et al. 2009; Yılmaz et al. 2010; Dural et al. 2011; Manaşırlı et al. 2015; Dural Eken and Akman 2018, Duysak 2019; Yücel and Çam 2021). Although relationships among the metal bioaccumulation and DNA damage in the marine ecosystem are very important for environmental safety, there is no research regarding the assessment of the genotoxic potential of Iskenderun Bay.

Recent investigations have been focused on electrochemical approaches in heavy metal ion detection. Electrochemical procedures are an easy technique and are suitable for fabricating small circuits in the form of mobile devices for in-situ monitoring of contaminated samples (Bansod et al. 2017). It is the central issue to have a facile and inexpensive technique in order to selectively and sensitively determine toxic chemical pollutants. However, there exist few studies about these techniques in the monitoring of the environmental (Pujol et al. 2014; Qi et al. 2017). With this background, the aim of this study was to report the genetic damage and the accumulation of trace metals of $L$. aurata as a bioindicator species in the Payas coast of Iskenderun Bay, North-Eastern Mediterranean by COMET Assay and electrochemical technique. 


\section{Material And Methods}

\subsection{Sampling area}

The sampling site was chosen at the Payas coast of Iskenderun Bay (Turkey), the North-Eastern Mediterranean. The Payas coast $\left(36^{\circ} 45^{\prime} 13.9^{\prime \prime} \mathrm{N} 36^{\circ} 11^{\prime} 31.6 " \mathrm{E}\right)$ is the downstream of the Payas Stream where flows into the Mediterranean Sea and surrounded by intense industrial activities (such as iron-steel factories and iron-steel waste plant), chemical manufacturing, domestic drainage, and shipping (Duysak 2019) (Fig. 1). Cultured golden grey mullet and culture tanks seawater samples were also used as a reference site for genotoxicological analyses. Cultured golden grey mullet ( $L$. aurata) was supplied by the Iskenderun Technical University Aquaculture Research Center (Iskenderun, Turkey). Coastal seawater and fish specimens were seasonally sampled at the sampling site for one year (September 2019 to July 2020).

\subsection{Sampling Procedure}

Water samples were taken $2 \mathrm{~m}$ below the surface using sterile $500 \mathrm{~mL}$ glass bottles and acidified to $\mathrm{pH} 2$ with ultrapure $6 \mathrm{M} \mathrm{HNO}_{3}$. Samples taken in triplicate were brought to the laboratory as quickly as possible and cooled at $4^{\circ} \mathrm{C}$ until analysis. Live samples of mullet (10 individuals from each sampling site) were captured using a fyke net by local fishermen and brought to the laboratory as quickly as possible. In laboratory, measurements of $L$. aurata were taken total body length and wet weight (Table 1 ). Temperature, dissolved oxygen and $\mathrm{pH}$ in waters of sampling site and culture tanks were taken in situ by a YSI type oxygen-meter $\mathrm{pH}$ meter. The salinity, electrical conductivity, and total dissolved solids of the samples were taken by the portable YSI type salinity/conductivity meter.

Table 1

Mean length and weight of $L$. aurata from Payas coast of the North-Eastern Mediterranean and Reference site $(x \mathbb{\|} \backslash \pm S D)(n=10)$

\begin{tabular}{|c|c|c|c|c|}
\hline & Winter & Spring & Summer & Autumn \\
\hline \multicolumn{5}{|l|}{ Sampling site } \\
\hline Length (cm) & $12.22 \pm 1.02$ & $15.26 \pm 5.07$ & $17.10 \pm 10.83$ & $18.68 \pm 6.40$ \\
\hline Weight (g) & $16.21 \pm 2.65$ & $38.98 \pm 12.78$ & $43.80 \pm 25.05$ & $61.77 \pm 40.46$ \\
\hline \multicolumn{5}{|c|}{ Reference Site } \\
\hline Length (cm) & $19.85 \pm 1.75$ & $19.60 \pm 1.05$ & $21.18 \pm 2.15$ & $21.05 \pm 1.75$ \\
\hline Weight (g) & $250.26 \pm 42.60$ & $275.65 \pm 30.38$ & $381.84 \pm 42.02$ & $360.45 \pm 35.47$ \\
\hline
\end{tabular}

\subsection{Metal Analysis}

\subsubsection{Tissue sample}


Trace metal determination in muscle and liver tissue was performed by an acid digestion adapted from AOAC Official Method 999.10 (2002) on a wet weight basis. Firstly, $1 \mathrm{~g}$ of the sample (taken with a scalpel from the central part of the muscle and liver) was digested by a mixture of $10 \mathrm{~mL}$ of nitric acid $\left(\mathrm{HNO}_{3}\right), 0.25 \mathrm{~mL}$ of hydrogen peroxide $\left(\mathrm{H}_{2} \mathrm{O}_{2}\right)$ and kept in a bath-water at $60^{\circ} \mathrm{C}$ for one hour to perform acid digestion, after which the samples were allowed to cool at room temperature. Later, the solution was filtered and increased to $100 \mathrm{~mL}$ with distilled and deionized water. After the acid digestion, the metals concentration was determined by electrochemical method in triplicate. The values of heavy metal content of the samples were measured as $\mu \mathrm{g} \mathrm{g}^{-1}$ wet weight $(\mathrm{ww})$ respectively by mathematical methods. In addition, analytical grade of chemicals and standard solutions (SIGMA) were used in this research.

\subsubsection{Evaluation Of Trace Metals By Electrochemical Method}

Cadmium (Cd), Lead (Pb), Mercury ( $\mathrm{Hg})$, Chromium (Cr), Cobalt (Co), Iron (Fe), Zinc (Zn) Copper (Cu), Nickel ( $\mathrm{Ni}$ ) and Mangan ( $\mathrm{Mn}$ ) were determined by electrochemical measurements, with samples being previously acid digested. Electrochemical measurements were carried out by Gamry Reference 600 workstation (Gamry, USA) and BAS-100B electrochemical analyser. Triple electrode system comprising glassy carbon electrode as indicator electrode, $\mathrm{Ag} / \mathrm{AgCl} / \mathrm{KCl}$ (sat) as reference electrode, and platinum wire as auxiliary electrode were employed for all electrochemical measurements. Moreover, the cleaning protocol of glassy carbon electrodes were performed according to our previous paper (Yola et al. 2012). After the supporting electrolyte $(\mathrm{pH} 7.4$, phosphate buffer, $3.0 \mathrm{~mL})$ put into the electrochemical cell, the standard solutions ( $\mathrm{Cr}, \mathrm{Cu}, \mathrm{Pb}, \mathrm{Co}, \mathrm{Cd}, \mathrm{Fe}, \mathrm{Ni}, \mathrm{Zn}$ and $\mathrm{Mn}$ ) were added into phosphate buffer by micropipette. This process was separately carried out for each metal ion. Before the measurements, the sample solutions were passed through argon gas $(99.999 \%$ ) during $15 \mathrm{~min}$. Then, the electrochemical potential scan was applied to electrochemical cell including trace metal solutions in range from - 1.00 to $0.0 \mathrm{~V}$. After the recording of electrochemical voltammograms based on at pulse height of $5 \mathrm{mV}$, square wave amplitude of $50 \mathrm{mV}$ and frequency of $50 \mathrm{~Hz}$, the peak signals $(\mu \mathrm{A})$ attributing to trace metal concentrations were evaluated for trace metal detections.

\subsection{Comet Assay}

Comet assay was done according to cellular dissociation technique improved from Cavalcante et al. (2008). Firstly, Liver and gill tissues of L. aurata were homogenized and centrifuged at $3000 \mathrm{rpm}$ at $4^{\circ} \mathrm{C}$ for $5 \mathrm{~min}$ for the cell suspension, and then the cell pellet was retained. Singh et al. (1988) was followed for performing the single cell gel electrophoresis. The slides were neutralized with ice cold $0.4 \mathrm{M}$ Tris buffer ( $\mathrm{pH}$ 7.5), stained with $80 \mathrm{ml}$ ethidium bromide $\left(20 \mathrm{mg} \mathrm{mL}^{-1}\right)$. The slides were then examined at X400 magnification using a fluorescence microscope (Carl Zeiss Aksiostar Plus). Images of 100 cells from each sample (gill and liver) were monitored and scored as proposed by Collins (2004) by classifying the nucleoids, which were assigned to one of five classes $(0-4$; with 0 signifying no visible tail and 4 almost all DNA in the tail) according to intensity of the comet tail. For comparison of the data from the comet assay, the damage percentage (\%DF), the arbitrary units values (AU) and genetic damage index (GDI) were calculated as defined by Pitarque et al. (1999) and Collins (2004). 


\subsection{Statistical Analysis}

Before statistical treatment, all collected data were tested for the normality (Shapiro-Wilk test) and homogeneity (Levene analyse test). Furthermore, one-way analysis of variance (ANOVA) was applied for significance assessments $(P<0.05)$ (Zar 1996). Principal component analysis (PCA) was applied to define the most important parameters involved in DNA damage. Additionally, Pearson's chi- squared test was also used to determine the relationship between trace metal and DNA damage (Zheng et al. 2016). The statistical analysis was made using IBM SPSS Statistics 21 and R-Studio.

\section{Results}

\subsection{Physicochemical parameters}

The seasonally analysed physicochemical parameters in the sampling and reference sites during one year are presented in Table 2. At the reference site (cultured tanks), average temperature $25.30^{\circ} \mathrm{C}$, dissolved oxygen $6.55 \mathrm{mg} \mathrm{L}^{-1}$, pH 8.20, salinity $36.12 \%$, electrical conductivity $35200 \mu \mathrm{sm}^{-1}$ and total dissolved solids $45.00 \mathrm{~g} \mathrm{~L}^{-1}$ were determined for one year.

Table 2

Comparison of some physicochemical parameters (mean \pm standard deviation) of the reference site and Payas coastal seawater samples of the North-Eastern Mediterranean.

\begin{tabular}{|c|c|c|c|c|c|}
\hline \multicolumn{6}{|c|}{ Sampling Site } \\
\hline & $\begin{array}{l}\text { Reference } \\
\text { Site }\end{array}$ & Winter & Spring & Summer & Autumn \\
\hline Temperature $\left({ }^{\circ} \mathrm{C}\right)$ & $25.30 \pm 1.50$ & $\begin{array}{l}18.05 \pm \\
0.50\end{array}$ & $\begin{array}{l}22.60 \pm \\
0.56\end{array}$ & $\begin{array}{l}30.40 \pm \\
0.65\end{array}$ & $\begin{array}{l}29.50 \pm \\
1.05\end{array}$ \\
\hline D.O $\left(\mathrm{mg} \mathrm{L}^{-1}\right)$ & $6.55 \pm 0.06$ & $\begin{array}{l}7.50 \pm \\
0.16\end{array}$ & $\begin{array}{l}8.55 \pm \\
0.06\end{array}$ & $\begin{array}{l}8.12 \pm \\
0.12\end{array}$ & $\begin{array}{l}7.35 \pm \\
0.07\end{array}$ \\
\hline $\mathrm{pH}$ & $8.20 \pm 0.05$ & $\begin{array}{l}8.45 \pm \\
0.04\end{array}$ & $\begin{array}{l}8.25 \pm \\
0.14\end{array}$ & $\begin{array}{l}8.52 \pm \\
0.17\end{array}$ & $\begin{array}{l}8.10 \pm \\
0.08\end{array}$ \\
\hline Salinity $\left(\%_{0}\right)$ & $36.12 \pm 0.52$ & $\begin{array}{l}37.12 \pm \\
0.55\end{array}$ & $\begin{array}{l}37.12 \pm \\
1.45\end{array}$ & $\begin{array}{l}38.12 \pm \\
0.75\end{array}$ & $\begin{array}{l}38.85 \pm \\
1.15\end{array}$ \\
\hline $\begin{array}{l}\text { Electrical Conductivity ( } \mu \mathrm{S} \\
\mathrm{cm}^{-1} \text { ) }\end{array}$ & $35200 \pm 126$ & $\begin{array}{l}45500 \pm \\
150\end{array}$ & $\begin{array}{l}47750 \pm \\
120\end{array}$ & $\begin{array}{l}48100 \pm \\
135\end{array}$ & $\begin{array}{l}49300 \pm \\
196\end{array}$ \\
\hline Total Dissolved solid $\left(\mathrm{g} \mathrm{L}^{-1}\right)$ & $45.00 \pm 0.15$ & $\begin{array}{l}48.50 \pm \\
0.10\end{array}$ & $\begin{array}{l}47.30 \pm \\
0.15\end{array}$ & $\begin{array}{l}48.10 \pm \\
0.05\end{array}$ & $\begin{array}{l}46.85 \pm \\
0.10\end{array}$ \\
\hline
\end{tabular}

The average temperature values of the sampling site were between $18.05^{\circ} \mathrm{C}$ and $30.40^{\circ} \mathrm{C}$ for one year. It is known that the temperature of the seawater varies depending on the season and flows. The dissolved oxygen and $\mathrm{pH}$ and salinity values of the sampling sites were between $7.35-8.55 \mathrm{mg} \mathrm{L}^{-1}, 8.10-8.52$, and 
$37.12-38.85 \%$, respectively. The measurements of electrical conductivity and total dissolved solids were obtained between $45500-49300 \mu \mathrm{S} \mathrm{cm}^{-1}$ and $46.85-48.50 \mathrm{~g} \mathrm{~L}^{-1}$, respectively. The coastal seawater samples of sampling site were suitable in the quality range with respect to the temperature, $\mathrm{pH}$ and salinity parameters as described by Coastal Waters Quality Criteria of Turkish Environmental Guidelines, 2015.

\subsection{Bioaccumulation}

Mean values of $\mathrm{Cd}, \mathrm{Pb}, \mathrm{Hg}, \mathrm{Cr}, \mathrm{Co}, \mathrm{Fe}, \mathrm{Zn}, \mathrm{Cu}, \mathrm{Ni}$ and $\mathrm{Mn}$ concentrations in different tissues (muscle and liver) of $L$. aurata collected from the Payas coast and references site for one year are given in Table 3 , Table 4 and Table 5. 
Table 3

Trace metal concentrations in the liver of Liza aurata in Payas coast of the North-Eastern Mediterranean and Reference site (concentration unit as $\mu \mathrm{g} \mathrm{g}^{-1} \mathrm{ww}$.)

\begin{tabular}{|c|c|c|c|c|c|c|}
\hline Seasons/Metals & STATIONS & & & & & \\
\hline WINTER & Payas Site & $\begin{array}{l}\text { Reference } \\
\text { Site }\end{array}$ & $\begin{array}{l}\text { EU } \\
(2005)\end{array}$ & $\begin{array}{l}\text { EPA } \\
(1989)\end{array}$ & $\begin{array}{l}\text { WHO } \\
\text { (1989) }\end{array}$ & $\begin{array}{l}\text { TFC } \\
\text { (2011) }\end{array}$ \\
\hline Cd & $\begin{array}{l}0.0219 \pm \\
0.008\end{array}$ & $\begin{array}{l}0.019 \pm \\
0.005\end{array}$ & 0.05 & 1.4 & 1.0 & 0.05 \\
\hline $\mathrm{Pb}^{* \star}$ & $1.647 \pm 0.338$ & $\begin{array}{l}0.135 \pm \\
0.010\end{array}$ & 0.2 & 1.0 & 2.0 & 0.3 \\
\hline $\mathrm{Hg}^{\star \star \star}$ & $0.089 \pm 0.007$ & $\begin{array}{l}0.0091 \pm \\
0.006\end{array}$ & 0.02 & 0.1 & 0.4 & 0.50 \\
\hline $\mathrm{Cr}^{* *}$ & $1.460 \pm 0.253$ & $\begin{array}{l}0.406 \pm \\
0.097\end{array}$ & - & 4.1 & - & - \\
\hline $\mathrm{Co}^{*}$ & $0.013 \pm 0.012$ & $\begin{array}{l}0.053 \pm \\
0.005\end{array}$ & - & - & - & - \\
\hline $\mathrm{Fe}$ & $\begin{array}{l}69.646 \pm \\
4.090\end{array}$ & $\begin{array}{l}54.904 \pm \\
9.125\end{array}$ & - & 410 & 100 & 50 \\
\hline $\mathrm{Zn}^{\star \star \star}$ & $\begin{array}{l}28.825 \pm \\
1.216\end{array}$ & $\begin{array}{l}8.090 \pm \\
0.895\end{array}$ & 50 & 410 & 100 & 50 \\
\hline $\mathrm{Cu}^{\star \star *}$ & $5.745 \pm 0.505$ & $\begin{array}{l}1.230 \pm \\
0.211\end{array}$ & 10 & 54 & 30 & 20 \\
\hline $\mathrm{Ni}$ & $0.847 \pm 0.112$ & $\begin{array}{l}0.878 \pm \\
0.122\end{array}$ & - & 4.6 & - & - \\
\hline $\mathrm{Mn}^{* *}$ & $0.510 \pm 0.129$ & $\begin{array}{l}2.615 \pm \\
0.440\end{array}$ & - & 100 & 1.0 & 20 \\
\hline \multicolumn{7}{|l|}{ SPRING } \\
\hline $\mathrm{Cd}^{*}$ & $0.255 \pm 0.119$ & $\begin{array}{l}0.017 \pm \\
0.008\end{array}$ & 0.05 & 1.4 & 1.0 & 0.05 \\
\hline $\mathrm{Pb}^{* *}$ & $1.607 \pm 0.138$ & $\begin{array}{l}0.110 \pm \\
0.032\end{array}$ & 0.2 & 1.0 & 2.0 & 0.3 \\
\hline $\mathrm{Hg}^{*}$ & $0.143 \pm 0.057$ & $\begin{array}{l}0.011 \pm \\
0.006\end{array}$ & 0.02 & 0.1 & 0.4 & 0.50 \\
\hline $\mathrm{Cr}^{*}$ & $1.793 \pm 0.772$ & $\begin{array}{l}0.306 \pm \\
0.106\end{array}$ & - & 4.1 & - & - \\
\hline
\end{tabular}

The data are shown as arithmetic mean \pm standard deviation. Indicate significance level between different tissues of $L$. aurata collected from the sampling site and reference station $(*, P<0.05 ; * \star, P<$ $0.01, \star \star \star P<0.001)$. 


\section{Seasons/Metals STATIONS}

\begin{tabular}{|c|c|c|c|c|c|c|}
\hline $\mathrm{Co}^{*}$ & $0.677 \pm 0.315$ & $\begin{array}{l}0.117 \pm \\
0.055\end{array}$ & - & - & - & - \\
\hline $\mathrm{Fe}^{*}$ & $\begin{array}{l}106.979 \pm \\
17.361\end{array}$ & $\begin{array}{l}63.237 \pm \\
16.05\end{array}$ & - & 410 & 100 & 50 \\
\hline $\mathrm{Zn}^{* *}$ & $\begin{array}{l}45.491 \pm \\
10.829\end{array}$ & $\begin{array}{l}7.757 \pm \\
0.259\end{array}$ & 50 & 410 & 100 & 50 \\
\hline $\mathrm{Cu}^{* * *}$ & $8.745 \pm 0.505$ & $\begin{array}{l}1.059 \pm \\
0.126\end{array}$ & 10 & 54 & 30 & 20 \\
\hline $\mathrm{Ni}$ & $1.180 \pm 0.550$ & $\begin{array}{l}0.798 \pm \\
0.153\end{array}$ & - & 4.6 & - & - \\
\hline Mn & $2.844 \pm 1.282$ & $\begin{array}{l}1.948 \pm \\
1.111\end{array}$ & - & 100 & 1.0 & 20 \\
\hline
\end{tabular}

\section{SUMMER}

$\mathrm{Cd}^{\star \star}$

$0.768 \pm 0.192$

$0.020 \pm$

0.05

1.4

1.0

0.05

$\mathrm{Pb}^{* \star *}$

$5.058 \pm 0.428$

$0.151 \pm$

0.2

1.0

2.0

0.3

$\mathrm{Hg}^{\text {* }}$

$0.307 \pm 0.063$

$0.009 \pm$

0.002

0.02

0.1

0.4

0.50

$\mathrm{Cr}^{\star \star *}$

$2.019 \pm 0.108$

$0.406 \pm$

4.1

Co

$1.088 \pm 0.720$

0.097

$0.084 \pm$

0.056

$\mathrm{Fe}^{* \star *}$

$174.549 \pm$

6.988

$56.237 \pm$

14.365

$\mathrm{Zn}^{\text {** }}$

$85.220 \pm$

8.755

$7.090 \pm$

1.299

$\mathrm{Cu}^{\text {*t* }}$

$12.347 \pm$

0.368

$1.230 \pm$

0.360

$1.381 \pm 0.247$

$0.831 \pm$

0.155

Mn

$2.523 \pm 1.191$

$2.282 \pm$
1.090

\section{AUTUMN}

The data are shown as arithmetic mean \pm standard deviation. Indicate significance level between different tissues of $L$. aurata collected from the sampling site and reference station $(*, P<0.05 ; * \star, P<$ $0.01, \star \star \star P<0.001)$. 


\begin{tabular}{|c|c|c|c|c|c|c|}
\hline Seasons/Metals & STATIONS & & & & & \\
\hline $\mathrm{Cd}^{\star \star \star}$ & $1.610 \pm 0.110$ & $\begin{array}{l}0.023 \pm \\
0.011\end{array}$ & 0.05 & 1.4 & 1.0 & 0.05 \\
\hline $\mathrm{Pb}^{* *}$ & $2.627 \pm 0.601$ & $\begin{array}{l}0.159 \pm \\
0.035\end{array}$ & 0.2 & 1.0 & 2.0 & 0.3 \\
\hline $\mathrm{Hg}^{* *}$ & $0.189 \pm 0.061$ & $\begin{array}{l}0.008 \pm \\
0.001\end{array}$ & 0.02 & 0.1 & 0.4 & 0.50 \\
\hline $\mathrm{Cr}^{*}$ & $1.879 \pm 0.746$ & $\begin{array}{l}0.473 \pm \\
0.052\end{array}$ & - & 4.1 & - & - \\
\hline $\mathrm{Co}^{*}$ & $0.115 \pm 0.047$ & $\begin{array}{l}0.050 \pm \\
0.001\end{array}$ & - & - & - & - \\
\hline $\mathrm{Fe}^{\star \star *}$ & $\begin{array}{l}249.495 \pm \\
74.827\end{array}$ & $\begin{array}{l}55.904 \pm \\
5.718\end{array}$ & - & 410 & 100 & 50 \\
\hline $\mathrm{Zn}^{* *}$ & $\begin{array}{l}24.822 \pm \\
3.730\end{array}$ & $\begin{array}{l}9.090 \pm \\
0.506\end{array}$ & 50 & 410 & 100 & 50 \\
\hline $\mathrm{Cu}^{* \star *}$ & $\begin{array}{l}57.623 \pm \\
3.606\end{array}$ & $\begin{array}{l}1.563 \pm \\
0.280\end{array}$ & 10 & 54 & 30 & 20 \\
\hline $\mathrm{Ni}$ & $1.253 \pm 0.489$ & $\begin{array}{l}0.865 \pm \\
0.101\end{array}$ & - & 4.6 & - & - \\
\hline $\mathrm{Mn}^{* *}$ & $1.284 \pm 0.274$ & $\begin{array}{l}2.948 \pm \\
0.334\end{array}$ & - & 100 & 1.0 & 20 \\
\hline \multicolumn{7}{|c|}{$\begin{array}{l}\text { The data are shown as arithmetic mean } \pm \text { standard deviation. Indicate significance level between } \\
\text { different tissues of } L \text {. aurata collected from the sampling site and reference station }(*, P<0.05 ; * \star, P< \\
0.01, \star \star \star P<0.001) \text {. }\end{array}$} \\
\hline
\end{tabular}


Table 4

Trace metal concentrations in the muscle of Liza aurata in Payas coast of the North-Eastern Mediterranean and Reference site (concentration unit as $\mu \mathrm{g} \mathrm{g}^{-1} \mathrm{ww}$.)

\section{Seasons/Metals STATIONS}

\begin{tabular}{|c|c|c|c|c|c|c|}
\hline WINTER & Payas Site & $\begin{array}{l}\text { Reference } \\
\text { Site }\end{array}$ & $\begin{array}{l}\text { EU } \\
(2005)\end{array}$ & $\begin{array}{l}\text { EPA } \\
(1989)\end{array}$ & $\begin{array}{l}\text { WHO } \\
(1989)\end{array}$ & $\begin{array}{l}\text { TFC } \\
(2011)\end{array}$ \\
\hline $\mathrm{Cd}^{\star \star *}$ & $\begin{array}{l}0.058 \pm \\
0.005\end{array}$ & $\begin{array}{l}0.001 \pm \\
0.000\end{array}$ & 0.05 & 1.4 & 1.0 & 0.05 \\
\hline $\mathrm{Pb}$ & $\begin{array}{l}0.237 \pm \\
0.152\end{array}$ & $\begin{array}{l}0.032 \pm \\
0.005\end{array}$ & 0.2 & 1.0 & 2.0 & 0.3 \\
\hline $\mathrm{Hg}^{\star \star \star}$ & $\begin{array}{l}0.076 \pm \\
0.010\end{array}$ & $\begin{array}{l}0.001 \pm \\
0.000\end{array}$ & 0.02 & 0.1 & 0.4 & 0.50 \\
\hline $\mathrm{Cr}^{* \star *}$ & $\begin{array}{l}0.872 \pm \\
0.121\end{array}$ & $\begin{array}{l}0.087 \pm \\
0.027\end{array}$ & - & 4.1 & - & - \\
\hline Co & $\begin{array}{l}0.012 \pm \\
0.003\end{array}$ & $\begin{array}{l}0.017 \pm \\
0.004\end{array}$ & - & - & - & - \\
\hline $\mathrm{Fe}^{\star *}$ & $\begin{array}{l}19.177 \pm \\
1.852\end{array}$ & $\begin{array}{l}9.879 \pm \\
0.759\end{array}$ & - & 410 & 100 & 50 \\
\hline $\mathrm{Zn}^{* *}$ & $\begin{array}{l}13.996 \pm \\
1.517\end{array}$ & $\begin{array}{l}3.353 \pm \\
1.203\end{array}$ & 50 & 410 & 100 & 50 \\
\hline $\mathrm{Cu}^{* *}$ & $\begin{array}{l}1.763 \pm \\
0.188\end{array}$ & $\begin{array}{l}0.483 \pm \\
0.253\end{array}$ & 10 & 54 & 30 & 20 \\
\hline $\mathrm{Ni}$ & $\begin{array}{l}0.316 \pm \\
0.015\end{array}$ & $\begin{array}{l}0.166 \pm \\
0.151\end{array}$ & - & 4.6 & - & - \\
\hline Mn & $\begin{array}{l}0.434 \pm \\
0.080\end{array}$ & $\begin{array}{l}0.199 \pm \\
0.178\end{array}$ & - & 100 & 1.0 & 20 \\
\hline \multicolumn{7}{|l|}{ SPRING } \\
\hline Cd & $\begin{array}{l}0.103 \pm \\
0.071\end{array}$ & $\begin{array}{l}0.000 \pm \\
0.000\end{array}$ & 0.05 & 1.4 & 1.0 & 0.05 \\
\hline $\mathrm{Pb}^{* *}$ & $\begin{array}{l}0.709 \pm \\
0.139\end{array}$ & $\begin{array}{l}0.041 \pm \\
0.021\end{array}$ & 0.2 & 1.0 & 2.0 & 0.3 \\
\hline $\mathrm{Hg}^{*}$ & $\begin{array}{l}0.130 \pm \\
0.051\end{array}$ & $\begin{array}{l}0.000 \pm \\
0.000\end{array}$ & 0.02 & 0.1 & 0.4 & 0.50 \\
\hline $\mathrm{Cr}^{* *}$ & $\begin{array}{l}1.340 \pm \\
0.276\end{array}$ & $\begin{array}{l}0.078 \pm \\
0.019\end{array}$ & - & 4.1 & - & - \\
\hline
\end{tabular}

The data are shown as arithmetic mean \pm standard deviation. Indicate significance level between different tissues of $L$. aurata collected from the sampling site and reference station $(*, P<0.05 ; * \star, P<$ $0.01, * \star \star P<0.001)$. 


\section{Seasons/Metals STATIONS}

\begin{tabular}{|c|c|c|c|c|c|c|}
\hline Co & $\begin{array}{l}0.029 \pm \\
0.011\end{array}$ & $\begin{array}{l}0.010 \pm \\
0.004\end{array}$ & - & - & - & - \\
\hline $\mathrm{Fe}^{*}$ & $\begin{array}{l}25.012 \pm \\
4.360\end{array}$ & $\begin{array}{l}9.212 \pm \\
1.135\end{array}$ & - & 410 & 100 & 50 \\
\hline $\mathrm{Zn}^{\text {*** }}$ & $\begin{array}{l}19.108 \pm \\
2.014\end{array}$ & $\begin{array}{l}3.687 \pm \\
1.305\end{array}$ & 50 & 410 & 100 & 50 \\
\hline $\mathrm{Cu}^{* *}$ & $\begin{array}{l}1.366 \pm \\
0.344\end{array}$ & $\begin{array}{l}0.251 \pm \\
0.134\end{array}$ & 10 & 54 & 30 & 20 \\
\hline $\mathrm{Ni}^{* *}$ & $\begin{array}{l}0.621 \pm \\
0.066\end{array}$ & $\begin{array}{l}0.066 \pm \\
0.052\end{array}$ & - & 4.6 & - & - \\
\hline $\mathrm{Mn}^{* *}$ & $\begin{array}{l}0.787 \pm \\
0.216\end{array}$ & $\begin{array}{l}0.134 \pm \\
0.009\end{array}$ & - & 100 & 1.0 & 20 \\
\hline \multicolumn{7}{|c|}{ SUMMER } \\
\hline$C d^{*}$ & $\begin{array}{l}0.120 \pm \\
0.057\end{array}$ & $\begin{array}{l}0.001 \pm \\
0.000\end{array}$ & 0.05 & 1.4 & 1.0 & 0.05 \\
\hline $\mathrm{Pb}^{* *}$ & $\begin{array}{l}0.809 \pm \\
0.181\end{array}$ & $\begin{array}{l}0.028 \pm \\
0.009\end{array}$ & 0.2 & 1.0 & 2.0 & 0.3 \\
\hline $\mathrm{Hg}^{*}$ & $\begin{array}{l}0.154 \pm \\
0.063\end{array}$ & $\begin{array}{l}0.001 \pm \\
0.000\end{array}$ & 0.02 & 0.1 & 0.4 & 0.50 \\
\hline $\mathrm{Cr}^{* * *}$ & $\begin{array}{l}1.131 \pm \\
0.102\end{array}$ & $\begin{array}{l}0.091 \pm \\
0.012\end{array}$ & - & 4.1 & - & - \\
\hline Co & $\begin{array}{l}0.023 \pm \\
0.011\end{array}$ & $\begin{array}{l}0.013 \pm \\
0.009\end{array}$ & - & - & - & - \\
\hline $\mathrm{Fe}^{\star \star \star *}$ & $\begin{array}{l}28.679 \pm \\
2.333\end{array}$ & $\begin{array}{l}10.212 \pm \\
0.815\end{array}$ & - & 410 & 100 & 50 \\
\hline $\mathrm{Zn}^{* *}$ & $\begin{array}{l}29.775 \pm \\
7.309\end{array}$ & $\begin{array}{l}4.687 \pm \\
2.015\end{array}$ & 50 & 410 & 100 & 50 \\
\hline $\mathrm{Cu}^{* *}$ & $\begin{array}{l}1.700 \pm \\
0.267\end{array}$ & $\begin{array}{l}0.317 \pm \\
0.074\end{array}$ & 10 & 54 & 30 & 20 \\
\hline $\mathrm{Ni}^{* * *}$ & $\begin{array}{l}0.688 \pm \\
0.049\end{array}$ & $\begin{array}{l}0.100 \pm \\
0.070\end{array}$ & - & 4.6 & - & - \\
\hline $\mathrm{Mn}^{* *}$ & $\begin{array}{l}0.877 \pm \\
0.067\end{array}$ & $\begin{array}{l}0.167 \pm \\
0.126\end{array}$ & - & 100 & 1.0 & 20 \\
\hline AUTU & & & & & & \\
\hline
\end{tabular}

The data are shown as arithmetic mean \pm standard deviation. Indicate significance level between different tissues of $L$. aurata collected from the sampling site and reference station $(*, P<0.05 ; * \star, P<$ $0.01, * \star \star P<0.001)$. 


\begin{tabular}{|c|c|c|c|c|c|c|}
\hline Seasons/Metals & STATIONS & & & & & \\
\hline $\mathrm{Cd}^{*}$ & $\begin{array}{l}0.085 \pm \\
0.050\end{array}$ & $\begin{array}{l}0.001 \pm \\
0.000\end{array}$ & 0.05 & 1.4 & 1.0 & 0.05 \\
\hline $\mathrm{Pb}^{\star \star \star}$ & $\begin{array}{l}0.561 \pm \\
0.051\end{array}$ & $\begin{array}{l}0.035 \pm \\
0.007\end{array}$ & 0.2 & 1.0 & 2.0 & 0.3 \\
\hline $\mathrm{Hg}^{*}$ & $\begin{array}{l}0.153 \pm \\
0.001\end{array}$ & $\begin{array}{l}0.001 \pm \\
0.000\end{array}$ & 0.02 & 0.1 & 0.4 & 0.50 \\
\hline $\mathrm{Cr}^{\star \star \star *}$ & $\begin{array}{l}1.016 \pm \\
0.026\end{array}$ & $\begin{array}{l}0.094 \pm \\
0.016\end{array}$ & - & 4.1 & - & - \\
\hline Co & $\begin{array}{l}0.024 \pm \\
0.010\end{array}$ & $\begin{array}{l}0.023 \pm \\
0.026\end{array}$ & - & - & - & - \\
\hline $\mathrm{Fe}^{* *}$ & $\begin{array}{l}21.980 \pm \\
2.591\end{array}$ & $\begin{array}{l}10.545 \pm \\
0.401\end{array}$ & - & 410 & 100 & 50 \\
\hline $\mathrm{Zn}^{\star \star \star}$ & $\begin{array}{l}17.856 \pm \\
1.593\end{array}$ & $\begin{array}{l}3.687 \pm \\
1.788\end{array}$ & 50 & 410 & 100 & 50 \\
\hline $\mathrm{Cu}^{* *}$ & $\begin{array}{l}1.383 \pm \\
0.920\end{array}$ & $\begin{array}{l}0.350 \pm \\
0.126\end{array}$ & 10 & 54 & 30 & 20 \\
\hline $\mathrm{Ni}^{* \star}$ & $\begin{array}{l}0.602 \pm \\
0.055\end{array}$ & $\begin{array}{l}0.133 \pm \\
0.103\end{array}$ & - & 4.6 & - & - \\
\hline $\mathrm{Mn}^{* *}$ & $\begin{array}{l}0.778 \pm \\
0.110\end{array}$ & $\begin{array}{l}0.165 \pm \\
0.129\end{array}$ & - & 100 & 1.0 & 20 \\
\hline
\end{tabular}


Table 5

Trace metal concentrations in the liver and muscle tissues of Liza aurata in Payas coast of the NorthEastern Mediterranean and Reference site (concentration unit as $\mu \mathrm{g} \mathrm{g}^{-1}$ ww.) and guidelines.

\section{Annual/Metals STATIONS}

\begin{tabular}{|c|c|c|c|c|c|c|}
\hline LIVER & Payas Site & $\begin{array}{l}\text { Reference } \\
\text { Site }\end{array}$ & $\begin{array}{l}\text { EU } \\
(2005)\end{array}$ & $\begin{array}{l}\text { EPA } \\
\text { (1989) }\end{array}$ & $\begin{array}{l}\text { WHO } \\
\text { (1989) }\end{array}$ & $\begin{array}{l}\text { TFC } \\
(2011)\end{array}$ \\
\hline $\mathrm{Cd}^{* *}$ & $0.664 \pm 0.145$ & $0.020 \pm 0.009$ & 0.05 & 1.4 & 1.0 & 0.05 \\
\hline $\mathrm{Pb}^{* \star *}$ & $2.745 \pm 1.503$ & $0.139 \pm 0.034$ & 0.2 & 1.0 & 2.0 & 0.3 \\
\hline $\mathrm{Hg}^{* \star *}$ & $0.182 \pm 0.095$ & $0.009 \pm 0.002$ & 0.02 & 0.1 & 0.4 & 0.50 \\
\hline $\mathrm{Cr}^{* * *}$ & $1.788 \pm 0.519$ & $0.398 \pm 0.099$ & - & 4.1 & - & - \\
\hline $\mathrm{Co}^{*}$ & $0.473 \pm 0.565$ & $0.076 \pm 0.034$ & - & - & - & - \\
\hline $\mathrm{Fe}^{* *}$ & $\begin{array}{l}150.167 \pm \\
78.832\end{array}$ & $\begin{array}{l}57.570 \pm \\
10.838\end{array}$ & - & 410 & 100 & 50 \\
\hline $\mathrm{Zn}^{\star * \star}$ & $\begin{array}{l}46.090 \pm \\
25.698\end{array}$ & $8.007 \pm 1.039$ & 50 & 410 & 100 & 50 \\
\hline $\mathrm{Cu}^{*}$ & $\begin{array}{l}21.115 \pm \\
12.205\end{array}$ & $1.270 \pm 0.329$ & 10 & 54 & 30 & 20 \\
\hline $\mathrm{Ni}^{*}$ & $1.165 \pm 0.393$ & $0.843 \pm 0.119$ & - & 4.6 & - & - \\
\hline Mn & $1.790 \pm 0.358$ & $2.448 \pm 0.804$ & - & 100 & 1.0 & 20 \\
\hline \multicolumn{7}{|c|}{ MUSCLE } \\
\hline $\mathrm{Cd}^{\star \star *}$ & $0.091 \pm 0.050$ & $0.001 \pm 0.000$ & 0.05 & 1.4 & 1.0 & 0.05 \\
\hline $\mathrm{Pb}^{\star \star *}$ & $0.579 \pm 0.255$ & $0.034 \pm 0.012$ & 0.2 & 1.0 & 2.0 & 0.3 \\
\hline $\mathrm{Hg}^{\star * *}$ & $0.128 \pm 0.057$ & $0.001 \pm 0.000$ & 0.02 & 0.1 & 0.4 & 0.50 \\
\hline $\mathrm{Cr}^{\star \star *}$ & $1.090 \pm 0.224$ & $0.087 \pm 0.017$ & - & 4.1 & - & - \\
\hline Co & $0.022 \pm 0.010$ & $0.016 \pm 0.014$ & - & - & - & - \\
\hline $\mathrm{Fe}^{\star \star *}$ & $23.712 \pm 4.463$ & $9.962 \pm 0.868$ & - & 410 & 100 & 50 \\
\hline $\mathrm{Zn}^{* * *}$ & $20.184 \pm 6.975$ & $3.853 \pm 1.668$ & 50 & 410 & 100 & 50 \\
\hline
\end{tabular}

The data are shown as arithmetic mean \pm standard deviation. Indicate significance level between different tissues of $L$. aurata collected from the sampling site and reference station $(*, P<0.05 ; * \star, P<$ $0.01, \star \star \star P<0.001)$. TFC: Turkish Food Codex, Communiqué on Maximum Limits of Contaminants in Foodstuffs in Turkey. EPA: Environmental Protection Agency; EU: European Union, WHO: World Health Organization 


\begin{tabular}{|c|c|c|c|c|c|c|}
\hline Annual/Metals & STATIONS & & & & & \\
\hline $\mathrm{Cu}^{\star \star *}$ & $1.553 \pm 0.315$ & $0.350 \pm 0.194$ & 10 & 54 & 30 & 20 \\
\hline $\mathrm{Ni}^{* \star *}$ & $0.557 \pm 0.154$ & $0.116 \pm 0.098$ & - & 4.6 & - & - \\
\hline$M n^{* * *}$ & $0.719 \pm 0.209$ & $0.166 \pm 0.117$ & - & 100 & 1.0 & 20 \\
\hline \multicolumn{7}{|c|}{$\begin{array}{l}\text { The data are shown as arithmetic mean } \pm \text { standard deviation. Indicate significance level between } \\
\text { different tissues of } L \text {. aurata collected from the sampling site and reference station }(*, P<0.05 ; * \star \\
0.01, * \star *<<<0.001) \text {. TFC: Turkish Food Codex, Communiqué on Maximum Limits of Contaminants in } \\
\text { Foodstuffs in Turkey. EPA: Environmental Protection Agency; EU: European Union, WHO: World Health } \\
\text { Organization }\end{array}$} \\
\hline
\end{tabular}

The concentrations of all the trace metals, except Co were significantly different in the liver and muscle tissues of $L$. aurata collected from the Payas coast and References site for all seasons $(P<0.01, P<$ 0.001 ) (Table 3,4$)$. $\mathrm{Cd}$ and $\mathrm{Pb}$ concentrations at Payas coast were highly exceed the maximum limits allowed by the TFC (2011), EU (2005) in summer and autumn that were sufficient to have negative effects on coastal ecosystems.

During the study period, the highest $\mathrm{Cd}$ accumulation in liver tissues was determined in autumn at Payas coast $\left(1.610 \pm 0.110 \mu \mathrm{g} \mathrm{g}^{-1}\right)$, and the lowest was determined in spring in the reference site $(0.017 \pm 0.008$ $\mu \mathrm{g} \mathrm{g}^{-1}$ ). Except winter season, $\mathrm{Cd}$ showed significant differences between studied sites for all seasons ( $P$ $<0.01)($ Table 3, 4). The highest $\mathrm{Pb}$ accumulation was found in summer at Payas coast $(5.058 \pm 0.428 \mu \mathrm{g}$ $\left.\mathrm{g}^{-1}\right)$, and the lowest was in summer at the muscle tissues of reference site $\left(0.028 \pm 0.009 \mu \mathrm{g} \mathrm{g}^{-1}\right)$. For all seasons, Pb accumulation was higher than the maximum limits of TFC (2011) and EU (2005) at liver and muscle tissues in Payas coast. Significant differences in the concentration of Fe in liver and muscle tissues was detected among the Payas coast and reference site $(P<0.05)$ (Table 3 and Table 4). The highest Fe concentration in liver tissues ranged from $249.495 \pm 74.827$ to $69.646 \pm 4.090 \mathrm{ug} \mathrm{g}^{-1}$ at sampling site that was highly over the values described by the TFC (2011), WHO (1989) at both all seasons and annual vales that were sufficient enough to give negative effects on coastal ecosystem (Table 5). In the liver tissue, the highest content of $\mathrm{Cu}\left(57.623 \pm 3.606 \mathrm{\mu g} \mathrm{g}^{-1}\right)$ was detected in Payas coast at autumn. Cu concentration in the Payas coast was above the EU (2005), EPA (1989), WHO (1989) and TFC (2011) limits at summer season.

Trace metal concentrations in the liver tissues of $L$. aurata can be ranged as follows: $\mathrm{Fe}>\mathrm{Zn}>\mathrm{Cu}>\mathrm{Pb}>$ $\mathrm{Cr}>\mathrm{Cd}>\mathrm{Hg}>\mathrm{Co}>\mathrm{Mn}>\mathrm{Ni}$ for studied site and Reference site; in the muscle tissues of $L$. aurata can be ranged as follows $\mathrm{Fe}>\mathrm{Zn}>\mathrm{Cu}>\mathrm{Cr}>\mathrm{Pb}>\mathrm{Cd}>\mathrm{Hg}>\mathrm{Co}>\mathrm{Mn}>\mathrm{Ni}$ for Payas coast and Reference site (Table 3 and Table 4). Accumulations of $\mathrm{Hg}, \mathrm{Cr}, \mathrm{Co}, \mathrm{Zn}, \mathrm{Ni}$ and $\mathrm{Mn}$ in liver and muscle tissues of $\mathrm{L}$. aurata collected from the Payas coast and References site weren't higher than the maximum limits (EU, 2005; EPA, 1989; WHO, 1989 and TFC, 2011) in both all seasons and annual (Table 3, Table 4 and Table 5). 
Hence, the assessment of human health risk wasn't conducted to estimate the risk posed by these metals.

\subsection{DNA Damage}

Percent damage frequency (DF \%), the arbitrary units values (AU) and genetic damage index (GDI \%) of DNA damage in $L$. aurata sampled from Payas coastal site and reference site was evaluated through comet assay and results are given in Table 6. 
Table 6

DNA damage in the gill and liver cells of $L$. aurata from Payas coast of the North-Eastern Mediterranean and Reference site analyzed by Comet Assay.

Payas coast Reference site

GILL

Damage Frequency (\%)

Winter ${ }^{\star \star}$

Spring $^{\star \star \star}$

Summer $^{\star \star \star}$

Autumn $^{* \star}$

ANNUAL ${ }^{* * *}$

Arbitrary Unit (AU)

Winter $^{\star \star}$

Spring ${ }^{\star}$

Summer ${ }^{\star \star \star}$

Autumn

ANNUAL ${ }^{* \star *}$

Damage Index (DI) (\%)

Winter $^{\star \star}$

Spring ${ }^{\star}$

Summer ${ }^{\star \star \star}$

Autumn

ANNUAL ${ }^{* * \star}$

\section{LIVER}

\section{Damage Frequency (\%)}

Winter $^{\star \star \star}$

$82.33 \pm 3.78$

$38.33 \pm 3.51$

The data are shown as arithmetic mean \pm standard deviation. Indicate significance level between different tissues of $L$. aurata collected from the sampling and reference site $\left({ }^{*}, P<0.05\right.$; $* \star, P<0.01$, $\star \star \star \mathrm{P}<0.001)$. 


\begin{tabular}{|c|c|c|}
\hline & Payas coast & Reference site \\
\hline Spring $^{\star \star}$ & $75.00 \pm 7.93$ & $39.33 \pm 6.42$ \\
\hline Summer ${ }^{\star \star \star}$ & $76.67 \pm 2.08$ & $35.33 \pm 0.57$ \\
\hline Autumn ${ }^{\star \star \star}$ & $79.00 \pm 1.01$ & $36.33 \pm 0.57$ \\
\hline ANNUAL ${ }^{* \star}$ & $78.25 \pm 4.82$ & $37.33 \pm 3.55$ \\
\hline \multicolumn{3}{|c|}{ Arbitrary Unit (AU) } \\
\hline Winter $^{\star}$ & $159.33 \pm 36.91$ & $79.33 \pm 20.79$ \\
\hline Spring ${ }^{\star \star \star}$ & $228.33 \pm 17.67$ & $74.00 \pm 18.52$ \\
\hline Summer ${ }^{\star \star \star}$ & $197.00 \pm 21.28$ & $67.33 \pm 6.65$ \\
\hline Autumn ${ }^{*}$ & $237.33 \pm 42.44$ & $70.33 \pm 7.51$ \\
\hline ANNUAL ${ }^{* \star *}$ & $205.50 \pm 41.64$ & $72.75 \pm 13.45$ \\
\hline \multicolumn{3}{|c|}{ Damage Index (DI) (\%) } \\
\hline Winter $^{*}$ & $1.59 \pm 0.36$ & $0.79 \pm 0.21$ \\
\hline Spring ${ }^{\star \star \star}$ & $2.28 \pm 0.17$ & $0.74 \pm 0.18$ \\
\hline Summer ${ }^{\star \star \star}$ & $1.97 \pm 0.21$ & $0.67 \pm 0.06$ \\
\hline Autumn ${ }^{\star \star}$ & $2.37 \pm 0.42$ & $0.70 \pm 0.07$ \\
\hline ANNUAL ${ }^{\star \star *}$ & $2.05 \pm 0.41$ & $0.72 \pm 0.13$ \\
\hline
\end{tabular}

In the COMET analysis, the DNA damage levels of both gill and liver tissues showed significant seasonal differences. Gill tissue in Payas coast site revealed the highest level of DNA damage ( $94.00 \pm 4.35 \%$ DF) in winter. However, the lowest level of DNA damage ( $35.33 \pm 0.57 \%$ DF) was observed at liver tissue at reference site in summer (Table 6). Relatively a higher level of DNA damage in gill than that liver was detected for all seasons and all sites ( $p<0.05)$. Annual analysis of DNA damage DF \%, AU and GDI \%) in $L$. aurata both from sampling and reference sites were significantly different $(p<0.001)$ from each other. Besides, the highest levels of DNA damage were detected at Payas coastal site with $94.00 \pm 4.35 \%$ DF, $275.00 \pm 20.95 \mathrm{AU}$ and $2.75 \pm 0.20 \% \mathrm{GDI}$ in the gill tissue (Table 6). Moreover, the highest levels of DNA 
damage were detected as $82.33 \pm 3.78 \% \mathrm{DF}, 237.33 \pm 42.44 \mathrm{AU}$ and $2.37 \pm 0.42 \% \mathrm{GDI}$ in the liver tissue at Payas coastal site (Table 6).

In the PCA, first two principal components loadings showed $67.408 \%$ and $9.836 \%$ of total variations, respectively (Table 7). Plotting the first principal components showed that the heavy metals variations could be related to DNA damage which are scattered along the principal components with high contributions (Fig. 2). Plotting the first two principal components showed that the heavy metals $\mathrm{Hg}, \mathrm{Pb}$, $\mathrm{Fe}, \mathrm{Zn}, \mathrm{Cr}$ and $\mathrm{Cu}$ (in the liver tissue) revealed strong contribution to the observed DNA damage (DF\%) that were vectored on the same direction along the principal component space (Fig. 2). Furthermore, $\mathrm{Cd}, \mathrm{Cu}$ and Fe metals (in liver tissue) were detected to be the most important parameters involved in DNA damage for AU and GDI parameters in the liver tissues. In additions, Zn and Cd (in liver and muscle) were also important parameters taking part in DNA damage for AU and GDI parameters in gill tissues (Fig. 2).

Table 7

Eigenvalue, proportion and cumulative contribution of heavy metal variables to DNA damage of $L$. aurata on first two Principal Components.

\begin{tabular}{|llll|}
\hline Component & Eigenvalues & \% of Variance & Cumulative \% \\
\hline 1 & 17.526 & 67.408 & 67.408 \\
\hline 2 & 2.557 & 9.836 & 77.243 \\
\hline 4 & 1.808 & 6.955 & 84.198 \\
\hline
\end{tabular}

\subsection{Correlation Between Trace Metals And Genetic Damage}

Positive significant $(\mathrm{P}<0.001)$ correlations were detected between $\mathrm{Cd}, \mathrm{Pb}, \mathrm{Hg}, \mathrm{Cr}, \mathrm{Fe}, \mathrm{Zn}$ and $\mathrm{Cu}$ in liver and DNA damage parameters in gill and liver cells (Fig. 3). No significant correlation between genotoxicity and $\mathrm{Co}, \mathrm{Ni}$ and $\mathrm{Mn}$ accumulations in liver of mullet were observed. In addition, Pearson correlation analysis revealed a positive significant $(\mathrm{P}<0.001)$ relationship between $\mathrm{Cd}, \mathrm{Pb}, \mathrm{Hg}, \mathrm{Cr}, \mathrm{Fe}, \mathrm{Zn}$, $\mathrm{Cu}, \mathrm{Ni}$ and $\mathrm{Mn}$ accumulations expect $\mathrm{Co}$ in muscle and DNA damage levels in gill and liver cells (Fig. 3)

\section{Discussion}

Heavy metals in coastal and marine ecosystems are considered as significant anthropogenic pollutants, which pose a serious risk to human health, aquatic species and ecosystem due to their toxicity and bioaccumulation features. Many of heavy metal are recognised to be lethal or oncogenic to humans. (Naser 2013). These toxic pollutants are of increasing concern regarding genotoxicity and leads to the use of sensible bioassays as a significant instrument to monitor Geno-toxicity of contaminated ecosystem. This study supplies the novel information on genotoxic responses of Liza aurata as bio indicator species in the Payas coast of Iskenderun Bay, the North-Eastern Mediterranean. 


\subsection{Physicochemical Parameters}

According to physicochemical results, the seawater samples of Payas coast of Iskenderun bay were suitable quality range with respect to the temperature, $\mathrm{pH}$ and salinity parameters as described by Coastal Waters Quality Criteria of Turkish Environmental Guidelines, 2015. When physicochemical parameters of coastal seawater in the literature are compared with the results of our study, it is clear that the values we obtained are compatible with these researches (Tekin Özcan 2015; Dural Eken and Akman 2017 , 2018). The levels of dissolved oxygen (7.35-8.55 $\left.\mathrm{mg} \mathrm{L}^{-1}\right), \mathrm{pH}(8.10-8.52)$, Electrical conductivity (45500-49300 $\left.\mu \mathrm{S} \mathrm{cm}^{-1}\right)$ and total dissolved solid (46.85-48.50 $\left.\mathrm{g} \mathrm{L}^{-1}\right)$ for all seasons in our findings were similar to stated amount of $\mathrm{pH}$, electrical conductivity, dissolved oxygen and total dissolved solid detected from Iskenderun Bay coastal seawater by Yücel and Çam (2021).

\subsection{Bioaccumulation}

The present study provides the first data set on accumulation of trace elements in golden grey mullet $(L$. aurata) from the Payas coast of Iskenderun Bay, the North-Eastern Mediterranean using electrochemical technique. Recently, much attention has been given on electrochemical detection methods which are inexpensive, highly sensitive and easily adaptable for in situ assessment with short analytical periods in the field of detection of heavy metal ions (Pujol et al. 2014; Qi et al. 2017). Electrochemical techniques are more economic, user friendly, reliable and suitable for in-field applications. These electrochemical techniques permit simple processes and well suited to fabricate on small circuits in the form of portable devices for in-situ observing of contaminated samples. The electrochemical techniques are also quick in terms of short analytical time in comparison to the other spectroscopic methods, authorizing on-line monitoring of environment (Bansod et al. 2017). Nevertheless, there are few studies about its use in the analysis of environmental and fish species. In this study, we reported that it can be used successfully the electrochemical technique in determination of trace metal concentrations in golden grey mullet species.

In the research area, $\mathrm{Cd}$ and $\mathrm{Pb}$ accumulations in liver and muscle tissues of golden grey mullet were exceed the maximum limits allowed by the TFC (2011), EU (2005) in summer and autumn that were sufficient to have negative effects on coastal ecosystems. In addition, Fe concentration in liver tissues was highly exceed the values allowed by the TFC (2011), WHO (1989) at sampling site in both all seasons and annual. Also, the highest content of $\mathrm{Cu}\left(57.623 \pm 3.606 \mu \mathrm{g} \mathrm{g}^{-1}\right)$ was detected in sampling site at autumn that was above the EU (2005), EPA (1989), WHO (1989) and TFC (2011) limits. Agca and Özdel (2013) reported that the highest $\mathrm{Cd}, \mathrm{Cu}, \mathrm{Fe}, \mathrm{Mn}, \mathrm{Pb}$ and $\mathrm{Zn}$ accumilations in soils of the same area were observed in industrial lands, particularly around the Iskenderun OIZ, having filter, nail, plastic, steel pipe, carton, engine, and steel factories. Yücel and Çam (2021) also reported similar heavy metal pollution from industrial and non-industrial coastal waters of Iskenderun Bay. When the results of metals in seawater were compared with international regulations that the average heavy metal levels for $\mathrm{Cd}, \mathrm{Pb}$, $\mathrm{Cu}$ and Ni obtained are generally exceed limit values. Their findings showed that coastal seawater samples in the Iskenderun Bay may have been affected by environmental contamination. In our study, all metal accumulations were higher in liver than muscle with varying concentrations. Generally, muscle is a 
less active tissue than liver which is the most metabolic tissue concerning xenobiotic metabolism. Thus, the differences among tissues may reveal differential physiological and metabolic capacities (Storelli et al. 2011). Hence, results of the previous studies (Türkmen et al. 2005; Yılmaz et al. 2010; Manaşırlı et al. 2015; Dural et al., 2011; Turan et al. 2020b) and the present study also approve that heavy metal concentrations in marine organisms are high in liver tissues.

\subsection{DNA damage and Correlation between Trace metals and Genotoxicity}

The DNA damage analyzed by the comet assay has been related to a wide range of genotoxic and cytotoxic compounds, such as trace metals (Lee and Steinert 2003). Damage frequency (DF\%) and arbitrary unit (AU) are commonly used for quantifying DNA strand breakage and represent the reliable parameter depending on the intensity of the comet tail (Collins 2004; De Andrade et al. 2004; Hosseinabadi et al. 2020). In the present study, the effects of the environmental pollutants were assessed using $L$. aurata as bioindicator species. The widespread distribution and resistance to different environmental conditions make this species a good bioindicator (Pacheco et al. 2005; Oliveira et al. 2007). The present study showed that the DNA damage level in the gill was significantly higher than in the liver for all seasons $(p<0.05)$, indicating that gills may be more susceptible to contaminants than other tissues due to high respiratory blood flow and continuous contact with the water. The subsidiary, similar types of researches stated that gill was sensible and goal tissue for monitoring of environmental pollution (Omar et al. 2012; Turan et al. 2020a, 2020b). Similarly, De Andrade et al. (2004) reported genotoxic levels of heavy metals to the mullet species (Mugil sp.) that the DNA damage in gill and liver cells was linked to the oxidative stress since gill revealed higher damage than that liver. In this study, $L$. aurata collected from the sampling site showed significant DNA damage as compared to those obtained from the reference site. The high damage levels were detected at Payas coastal site with $94.00 \pm 4.35 \%$ $\mathrm{DF}, 275.00 \pm 20.95 \mathrm{AU}$ and $2.75 \pm 0.20 \% \mathrm{GDI}$ in gill tissues and $82.33 \pm 3.78 \% \mathrm{DF}, 237.33 \pm 42.44 \mathrm{AU}$ and $2.37 \pm 0.42 \% \mathrm{GDI}$ liver tissue of $L$. aurata. Chronic contact with pollutants may cause an accumulation of DNA strand breaks in aquatic organisms such as fish since their DNA-repair capacity is much lower compared to that of other species (D'Costa et al. 2017). Also, D'Costa et al. (2017) reported that high levels of DNA damage are due to the accumulation of pollutants from the environment by conducted multiple regression analysis.

The PCA showed the pattern of the relationship of the heavy metals in tissues and the DNA of the golden grey mullet that the heavy metals $\mathrm{Hg}, \mathrm{Pb}, \mathrm{Fe}, \mathrm{Zn}, \mathrm{Cr}$ and $\mathrm{Cu}$ (in the liver tissue) revealed strong contribution to the observed DNA damage (DF\%). Moreover, Cd, Cu and Fe metals (in liver tissue) were observed to be the most important parameters taking a role in the DNA damage for AU and GDI parameters. Furthermore, the detected correlations between parameters showed a positive relationship between $\mathrm{Cd}, \mathrm{Pb}, \mathrm{Hg}, \mathrm{Cr}, \mathrm{Fe}, \mathrm{Zn}$ and $\mathrm{Cu}$ accumulations in liver and DNA damage parameters in gill and liver cells in the present study. Catalyze roles of heavy metals generate reactive oxygen species, which may cause oxidative stress and damage to tissues and macromolecules such as DNA, proteins, and lipids. Some studies also reported the higher DNA damage due to the exposure of heavy metals in mullet (Pacheco et al. 2005; Bouzenda et al. 2017) and other different fish species such as Arius arius, L. 
cephalus, C. gariepinus, A. anguilla (De Andrade et al. 2004; Abdel-Khalek 2015; D'Costa et al. 2017; Turan et al. 2020a, 2020b).

According to the present results, $\mathrm{Hg}, \mathrm{Pb}, \mathrm{Cd}, \mathrm{Cr}, \mathrm{Cu}, \mathrm{Fe}$ and $\mathrm{Zn}$, found to accumulate in the tissues of the golden grey mullet at Payas coast of Iskenderun Bay, could also be the cause of genotoxicity in L. aurata. These findings are in agreement with the results of D'Costa et al. (2017) which reported genotoxic effects of trace metals, such as $\mathrm{Fe}, \mathrm{Cu}, \mathrm{Cd}$ and $\mathrm{Pb}$, in coastal and marine environments. Similarly, Omar et al. (2012) reported that the genotoxic effects of trace metals such as $\mathrm{Cu}, \mathrm{Zn}, \mathrm{Fe}, \mathrm{Mn}$ and $\mathrm{Pb}$ in marine and estuarine environments. The high concentrations of these metals can be bound to DNA damage. Besides, the genotoxicity of mercury $(\mathrm{Hg})$ has been demonstrated in various research in different aquatic species. The mutagenic effect of $\mathrm{Hg}$ accumulation in fish tissues has also been confirmed by the increase of MN frequency in peripheral erythrocytes (Bolognesi et al. 1999).

\section{Conclusion}

The present study reveals novel data on the effect of heavy metals on toxiogenetic damage of $L$. aurata from Payas coast of Iskenderun bay, north-Eastern Mediterranean. Our study strongly supports that contaminated heavy metal caused DNA damage in gill and liver of L. aurata. The high DNA damage frequency at the $L$. aurata was observed in Payas coast of Iskenderun bay compared to the reference site due to pollutions that the detected high levels of $\mathrm{Cd}, \mathrm{Pb}$, Fe and $\mathrm{Cu}$ accumulation in golden grey mullet were exceed the maximum levels allowed by the national and international limit values. A significant positive correlation between $\mathrm{Cd}, \mathrm{Pb}, \mathrm{Hg}, \mathrm{Cr}, \mathrm{Fe}, \mathrm{Zn}$ and $\mathrm{Cu}$ accumulations and DNA damage parameters was reported in the present study. In addition, we reported firstly, that it can be used successfully the electrochemical technique in the determination of trace metal concentrations in golden grey mullet. The results of this study indicated that the studied sampling area in the Bay may have been affected by trace metal contamination. Pollution indicators and genotoxicity tests, combined with other physiological or biochemical parameters represent a vital instrument for biomonitoring coastal ecosystems.

\section{Declarations}

Acknowledgement: Thanks to The Scientific Research Projects Office, Iskenderun Technical University for financial support (2019 YP-01).

Conflict of Interest: The authors decelerate that they have no conflict of interests.

Availability of data and material: Data will be made available on reasonable request.

Ethical approval: All applicable international, national, and/or institutional guidelines for the care and use of animals were followed by the authors.

\section{References}


Abdel-Khalek AA (2015) Risk assessment, bioaccumulation of metals and kidney of Leuciscus cephalus following exposure to heavy metals in the Tur River, North Western Romania. Ecotoxicol Environ Saf 119:198-205.

Anandkumar A, Nagarajan R, Prabakaran K, Bing CH, Rajaram R, Li J, Du D (2019) Bioaccumulation of trace metals in the coastal Borneo (Malaysia) and health risk assessment. Mar Pollut Bull 145,:56-66.

AOAC (Association of Analytical Chemist) (2002) Official Method 999.10 Lead, Cadmium, Zinc, Cooper, and Iron in Foods, Atomic Absorption Spectrophotomoetry after Micowave Digestion.

Ayas D, Kosker AR, Agilkaya GS, Bakan M, Yaglioglu D (2018) The effects of age and individual size on metal levels of Serranus cabrilla (Linnaeus, 1758) from the Yeşilovacık Bay (Northeasthern Mediterranean, Turkey). NESciences 3:248-254.

Bansod B, Kumar T, Thakur R, Rana S, Singh I (2017) A review on various electrochemical techniques for heavy metal ions detection with different sensing platforms. Biosens Bioelectron 94:443-455.

Bogoni JA, Armiliato N, Araldi-Favassa CT, Techio VH (2014) Genotoxicity in Astyanax bimaculatus (Twospot Astyanax) exposed to the waters of Engano River (Brazil) as determined by micronucleus tests in erythrocytes. Arch Environ Contam Toxicol 66:441-449.

Bolognesi C, Landini E, Roggieri P, Rita Fabbri R, Viarengo A (1999) Genotoxicity Biomarkers in the Assessment of Heavy Metal Effects in Mussels: Experimental Studies, Environ Mol Mutagen 33:287-292.

Bouzenda R, Khebbeb NSMEH (2017) Assessment of pollution in the Gulf of Annaba (Algeria) by monthly measurements of two biomarkers in a fish species Liza aurata. J Entomol Zool Stud 5.

Cavalcante DGSM, Martinez CBR, Sofia SH (2008) Genotoxic effects of Roundup $®$ on the fish Prochilodus lineatus. Mutat Res Gen Toxicol Environ Mutagen 655:41-46.

Cazenave J, Bacchetta C, Parma MJ, Scarabotti PA, Wunderlin DA (2009) Multiple biomarkers responses in Prochilodus lineatus allowed assessing changes in the water quality of Salado River basin (Santa Fe, Argentina). Environ Pollut 157:3025-3033.

Collins A (2004) The comet assay for DNA damage and repair. Mol Biotechnol 26: 249-261.

D'Costa A, Shyama SK, Kumar MP (2017) Bioaccumulation of trace metals and total petroleum and genotoxicity responses in an edible fish population as indicators of marine pollution. Ecotoxicol Environ Safe 142:22-28.

Dalzochio T, Simões LAR, de Souza MS, Rodrigues GZP, Petry IE, Andriguetti NB, da Silva LB (2017) Water quality parameters, biomarkers and metal bioaccumulation in native fish captured in the llha River, southern Brazil. Chemosphere 189:609-618. 
De Andrade VM, Da Silva J, Da Silva FR, Heuser VD, Dias, JF, Yoneama ML, De Freitas TR (2004) Fish as bioindicators to assess the effects of pollution in two southern Brazilian rivers using the Comet assay and micronucleus test. Environ Mol Mut 44:459-468.

De Lemos CT, Rödel PM, Terra NR, de Oliveira NCDA, Erdtmann B (2007) River water genotoxicity evaluation using micronucleus assay in fish erythrocytes. Ecotoxicol Environ Safe 66:391-401.

Dural Eken M, Akman B (2017) Evaluation of Pollution from Rivers in Northeastern Mediterranean Region: Heavy Metals, Fresenius Environ Bull 26(7):4845-4850.

Dural Eken M, Akman B (2018) Assessment of heavy metal pollution of seston from freshwater resources poured into the Northeast Mediterranean region. Environmental Monitoring and Assessment, 190, 1-7.

Dural M, Genc E, Sangun MK, Güner Ö (2011) Accumulation of some heavy metals in Hysterothylacium aduncum (Nematoda) and its host sea bream, Sparus aurata (Sparidae) from North-Eastern Mediterranean Sea (Iskenderun Bay). Environ Monit Assess 174:147-155.

EPA (1989) Assessing Human Health Risks from Chemically Contaminated Fish and Shellfish: A Guidance Manual," EPA-503/8-89-002. United States Environmental Protection Agency, Office of Research and Development, Washington.

EU (European Union) (2005) Official Journal of the European Union, Commission Regulation (EC) No 78/2005. 2005, Amending Regulation (EC) No 466/2001 as regards heavy metals.

Hosseinabadi MB, Khanjani N, Atashi A, Norouzi P, Mirbadie SR, Mirzaii M (2020) The effect of vitamin E and $\mathrm{C}$ on comet assay indices and apoptosis in power plant workers: A double blind randomized controlled clinical trial. Mutat Res Gen Toxicol Environ Mutagen 850:503150.

Lee RF, Steinert S (2003) Use of the single cell gel electrophoresis / comet assay for detecting DNA damage in aquatic (marine and freshwater) animals. Rev Mutat Res 544:43-64.

Manasirli M, Avsar D, Yeldan H, Mavruk S (2015) Trace element (Fe, Cu and Zn) Accumulation in the muscle tissues of saurida. Undosquamis, Pagellus erythrinus and mullus barbatus in the Iskenderun Bay, Turkey. Fresenius Environ Bull 24:1601-1606.

Marcon AE, Ferreira DM, Moura MFV, Campos TFC, Amaral VS, Agnez-Lima LF, Medeiros SBR (2010) Genotoxic analysis in aquatic environment under influence of cyanobacteria, metal and radioactivity. Chemosphere 81:773-780.

Martins M, Costa PM (2017) Chapter 1: The Comet Assay in Aquatic (Eco) Genotoxicology Using NonConventional Model Organisms: Relevance, Constraints and Prospects, in Ecotoxicology and Genotoxicology. Non-traditional Aquatic Models, pp. 1-32. 
Naser HA (2013) Assessment and management of heavy metal pollution in the marine environment of the Arabian Gulf: A review. Mar Pollut Bull 72:6-13.

Omar WA, Zaghloul KH, Abdel-Khalek AA, Abo-Hegab S (2012) Genotoxic effects of metal pollution in two fish species, Oreochromis niloticus and Mugil cephalus, from highly degraded aquatic habitats. Mutat Res 746: 7-14.

Pacheco M, Santos MA, Teles M, Oliveira M, Rebelo JEÜ, Pombo L (2005) Biotransformation and genotoxic biomarkers in mullet species (Liza sp.) from a contaminated coastal lagoon (Ria de Aveiro, Portugal). Environ Monit Assess 107:133-153.

Pitarque M, Creus A, Marcos R, Hughes JA, Anderson D (1999) Examination of various biomarkers measuring genotoxic endpoints from Barcelona airport personel. Mutat Res Gen Toxicol Environ Mutagen 440:195-204.

Pujol L, Evrard D, Groenen-Serrano K, Freyssinier M, Ruffien-Cizsak A, Gros P (2014) Electrochemical sensors and devices for heavy metals assay in water: The French groups' contribution. Front Chem 2:19.

Qi X, Qian J, Chen T, Lu D, Chen B (2017) Electrochemical determination of Cu (II) ions based on Ag/Pd alloy for water quality early warning. Int J Electrochem Sci 12:5511-5520.

Singh NP, Mccoy MT, Tice RR, Schneider EL (1988) A Simple Technique for Quantitation of Low-Levels of DNA Damage in Individual Cells, Experiment Cell Res 175:184-191.

Storelli MM, Cuttone G, Marcotrigiano GO (2011) Distribution of trace elements in the tissues of smooth hound Mustelus mustelus (Linnaeus, 1758) from the southern-eastern waters of Mediterranean Sea (Italy). Environ Monit Assess 174:271-281.

TEG (2015) Turkish Enviromental Guidelines 2015 Publications of Turkish Foundation of Enviroment. Ministry of Agriculture and Rural Affairs.

TFC (Turkish Food Codex) (2011) Communiqué on Maximum Limits of Contaminants in Foodstuffs (Offical Newspaper Date: 29.12.2011-28157) Turkish Food Codex Contaminants Regulation, Ministry of Agriculture and Rural Affairs.

Turan C (2016) Biogeography and distribution of Mugilidae in the Mediterranean and the Black Sea, and North-East Atlantic. Biology, In book: Biology, Ecology and Culture of Grey Mullets (Mugilidae), CRC Press, Taylor and Francis Group, ISBN: 978-1-4822-5212-5, pp.116-127.

Turan C, Dural M, Oksuz A, Öztürk B (2009) Levels of heavy metals in some commercial fish species captured from the Black Sea and Mediterranean coast of Turkey. Bull Environ Contam Toxicol 82:601604. 
Turan F, Karan S, Ergenler A (2020a) Effect of heavy metals on toxicogenetic damage of European eels Anguilla anguilla. Environ Sci Pollut Res 27:38047-38055.

Turan F, Eken M, Ozyilmaz G, Karan S, Uluca H (2020b) Heavy metal bioaccumulation, oxidative stress and genotoxicity in African catfish Clarias gariepinus from Orontes river. Ecotoxicol 29:1522-1537.

Türkmen A, Türkmen M, Tepe Y, Akyurt I (2005) Heavy metals in three commercially valuable fish species from Iskenderun Bay, Northern East Mediterranean Sea, Turkey. Food Chem 91:167-172.

WHO (1989) Assessing Human Health Risks from Chemically Contaminated Fish and Shellfish: A Guidance Manual, WHO.

Yilmaz AB, Sangun MK, Yaglıoglu D, Turan C (2010) Metals (major essential to non-essential) composition of the different tissues of three demersal fish species from Iskenderun Bay, Turkey. Food Chem 123:410-415.

Yola ML, Atar N, Qureshi MS, Ustundag ZA, Solak O (2012) Electrochemically grafted etodolac film on glassy carbon for $\mathrm{Pb}$ (II) determination. Sens Actuators B Chem 171:1207-1215.

Yücel Y, Çam AR (2021) Assessment of industrial pollution effects in coastal seawater (Northeastern Mediterranean Sea) with chemometric approach. Int J Environ Anal Chem 101(1): 95-112.

Zar JH (1996) Biostatistical analysis, 3rd edn. Prentice Hall Inc, Englewood Cliffs.

Zheng XQ, Shi YJ, Lu YL, Xu XB (2016) Growth inhibition and DNA damage in the earthworm (Eisenia fetida) exposed to perfluorooctane sulphonate and perfluorooctanoic acid. Chem Ecol 32:103-116.

\section{Figures}




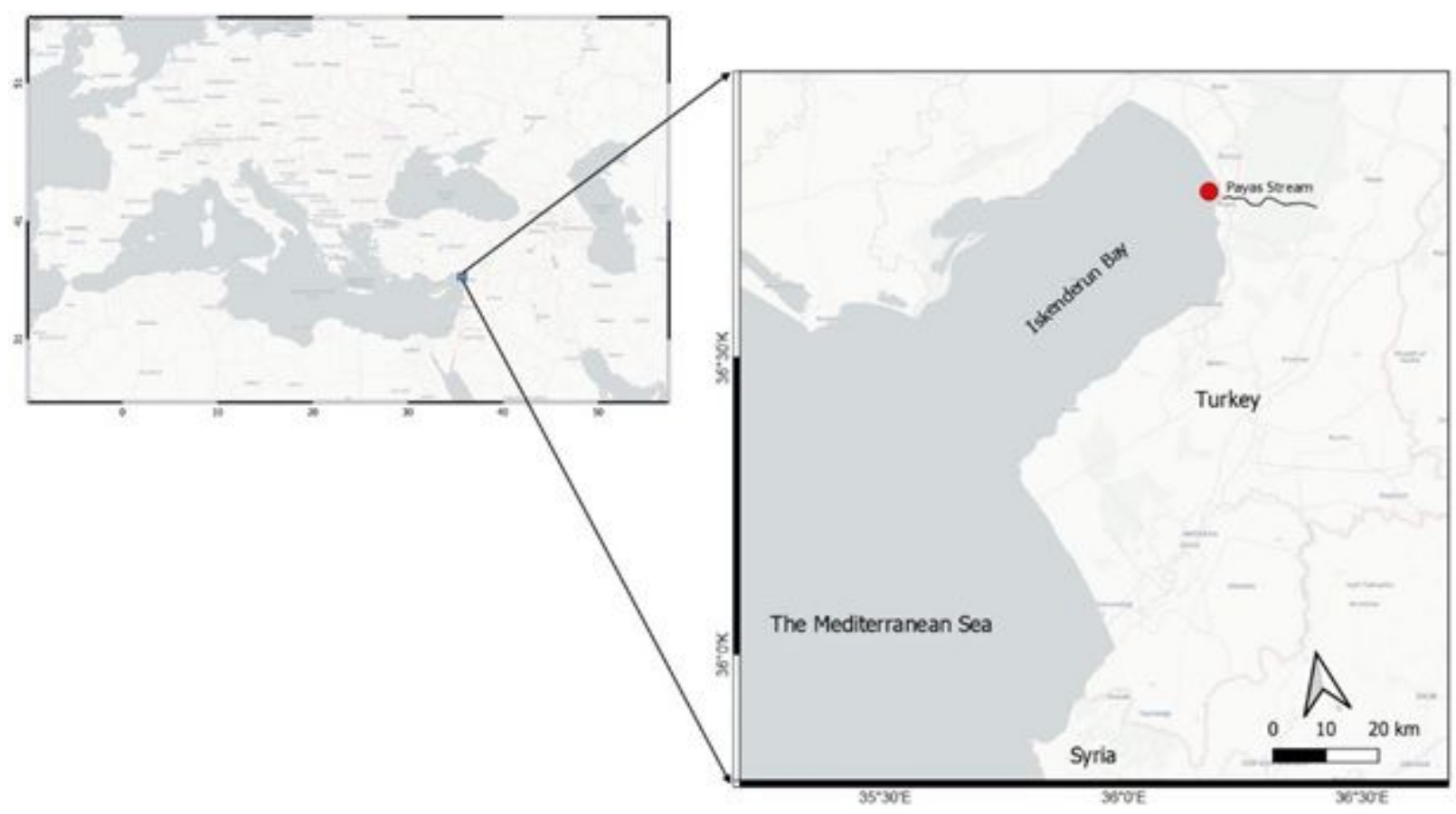

Figure 1

Map of sampling site (•) in the Payas coast (Turkey) of the North-Eastern Mediterranean. Note: The designations employed and the presentation of the material on this map do not imply the expression of any opinion whatsoever on the part of Research Square concerning the legal status of any country, territory, city or area or of its authorities, or concerning the delimitation of its frontiers or boundaries. This map has been provided by the authors. 


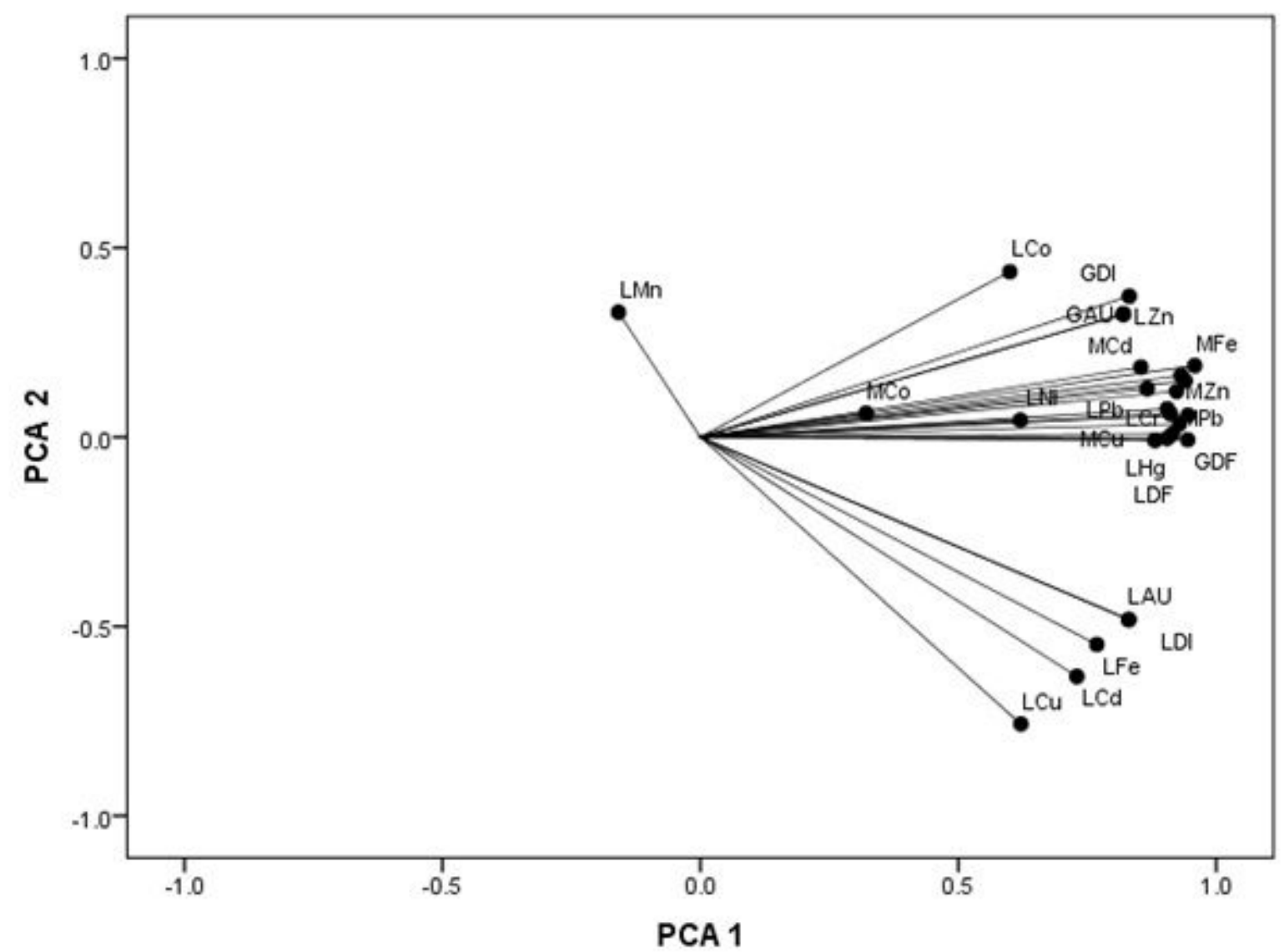

Figure 2

Contribution and relation of analyzed parameters on first two Principal Components 


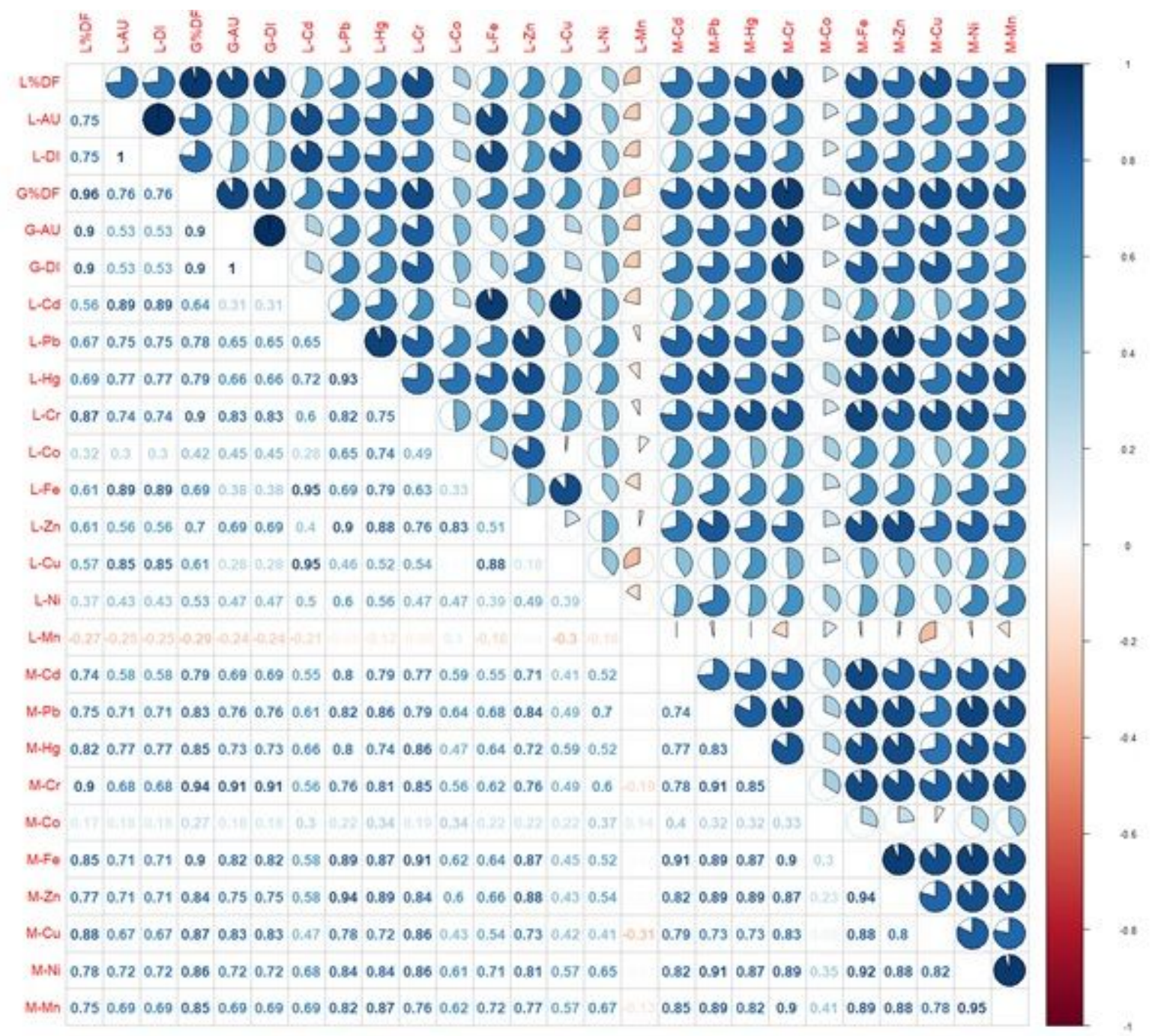

\section{Figure 3}

Heatmap of correlations between parameters with pie graph indicating the correlation level (above diagonal), and colored correlation levels on the bases of the scale color bar, indicating correlation between -1 and +1 . The specified significance level is $P<0.05$ 